\title{
International Assessment of DSM-5 and ICD-11 Personality Disorder Traits: Toward a Common Nosology in DSM-5.1
}

\author{
Bo Bach $^{\mathrm{a}}$ André Kerber ${ }^{\mathrm{b}}$ Anton Alujac Tim Bastiaens ${ }^{\mathrm{d}}$ Jared W. Keeley ${ }^{\mathrm{e}}$ Laurence Claes ${ }^{\mathrm{f}, \mathrm{t}}$ \\ Andrea Fossati $^{g}$ Fernando Gutierrez ${ }^{h}$ Sérgio E.S. Oliveira' ${ }^{i}$ Rute Pires $^{j}$ Karel D. Riegel $^{k}$ \\ Jean-Pierre Rolland ${ }^{l}$ Isabelle Roskam ${ }^{m}$ Martin Sellbom ${ }^{n}$ Antonella Somma ${ }^{g}$ \\ Lucas Spanemberg $^{\circ} \quad$ Włodzimierz Strus $^{p} \quad$ Jens C. Thimm ${ }^{q} \quad$ Aidan G.C. Wright $^{r}$ \\ Johannes Zimmermann ${ }^{\mathrm{s}}$ \\ ${ }^{a}$ Center for Personality Disorder Research, Psychiatric Research Unit, Region Zealand, Slagelse, Denmark; \\ ${ }^{b}$ Department of Psychology, Freie Universität Berlin, Berlin, Germany; ' CLleida Institute for Biomedical Research, \\ University of Lleida, Catalonia, Spain; ${ }^{d}$ University Psychiatric Centre, Katholieke Universiteit Leuven, Leuven,

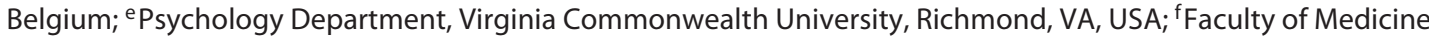 \\ and Health Sciences, University of Antwerp, Leuven, Belgium; ${ }^{9}$ Faculty of Psychology, Vita-Salute San Raffaele

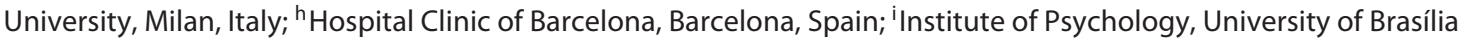 \\ (UnB), Brasília, Brazil; j CICPSI, Faculdade de Psicologia, Universidade de Lisboa, Lisbon, Portugal; ${ }^{k}$ Department of \\ Addictology, 1st Faculty of Medicine, Charles University of Prague, General University Hospital of Prague, Prague, \\ Czech Republic; 'STAPS, University Paris-Nanterre, Paris, France; ${ }^{m}$ Psychological Sciences Research Institute, \\ Université Catholique de Louvain (UCLouvain), Louvain-la-Neuve, Belgium; ${ }^{\mathrm{n}}$ Department of Psychology, University \\ of Otago, Dunedin, New Zealand; ${ }^{\circ}$ Escola de Medicina, Pontifícia Universidade Católica do Rio Grande do Sul

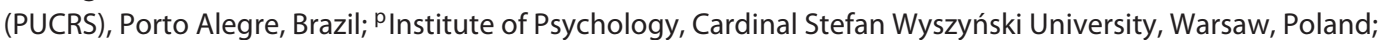 \\ 'Department of Psychology, The Arctic University of Norway (UiT), Tromsoe, Norway; ' Department of Psychology, \\ University of Pittsburgh, Pittsburgh, PA, USA; ${ }^{5}$ Department of Psychology, University of Kassel, Kassel, Germany; \\ ${ }^{\mathrm{t}}$ Faculty of Psychology and Educational Sciences, Katholieke Universiteit Leuven, Leuven, Belgium
}

\section{Keywords}

ICD-11 · DSM-5.1 - Personality disorder classification · Trait · Diagnosis

\section{Abstract \\ Introduction: The DSM-5 Alternative Model of Personality Disorders (AMPD) and the ICD-11 classification of personal- ity disorders (PD) are largely commensurate and, when com- bined, they delineate 6 trait domains: negative affectivity, detachment, antagonism/dissociality, disinhibition, anan- kastia, and psychoticism. Objective: The present study eval-}

uated the international validity of a brief 36-item patientreport measure that portrays all 6 domains simultaneously including 18 primary subfacets. Methods: We developed and employed a modified version of the Personality Inventory for DSM-5 - Brief Form Plus (PID5BF+). A total of 16,327 individuals were included, 2,347 of whom were patients. The expected 6-factor structure of facets was initially investigated in samples from Denmark ( $n=584)$, Germany $(n=1,271)$, and the USA ( $n=605)$ and subsequently replicated in both patient- and community samples from Italy, France, Switzerland, Belgium, Norway, Portugal, Spain, Poland, Czech Republic, the USA, and Brazil. Associations with interview-rated karger@karger.com

(C) 2020 S. Karger AG, Basel

www.karger.com/psp

Karger $\stackrel{2}{\circ}$
Bo Bach, $\mathrm{PhD}$

Center for Personality Disorder Research, Psychiatric Research Unit, Region Zealand Psychiatric Hospital Slagelse, Faelledvej 6, Building 3, 4th floor DK-4200 Slagelse (Denmark)

bobachsayad@gmail.com 
DSM-5 PD categories were also investigated. Results: Findings generally supported the empirical soundness and international robustness of the 6 domains including meaningful associations with familiar interview-rated PD types. Conclusions: The modified PID5BF+ may be employed internationally by clinicians and researchers for brief and reliable assessment of the 6 combined DSM- 5 and ICD- 11 domains, including 18 primary subfacets. This 6-domain framework may inform a future nosology for DSM-5.1 that is more reasonably aligned with the authoritative ICD-11 codes than the current DSM-5 AMPD model. The 36-item modified PID5BF+ scoring key is provided in online supplementary Appendix A see www.karger.com/doi/10.1159/000507589 (for all online suppl. material).

(c) 2020 S. Karger AG, Basel

\section{Introduction}

More than 1 out of 10 individuals in Western societies [1] and at least half of psychiatric outpatients [2] meet the diagnostic requirements for a personality disorder (PD), which is a central predictor of psychosocial impairment, comorbidity, and treatment outcomes [3]. However, scientific and clinical attention to PD varies from country to country due to culture, zeitgeist, and politics ${ }^{1}$ [4]. In many countries, PD are rarely diagnosed or described at all, apparently because practitioners find them too complicated and cumbersome to assess [5]. For such reasons, it seems imperative to introduce an internationally robust and feasible assessment framework that delineates the phenotypic variation in the expression of $\mathrm{PD}$ according to upcoming empirical nosology.

In both the ICD-11 classification of PD and the DSM5 Alternative Model of Personality Disorders (AMPD), Section III, trait domains are used as specifiers that contribute to the individual expression of personality disturbance in addition to the overall classification of severity (e.g., mild, moderate, or severe) $[6,7]$. Such specifiers are not diagnostic entities per se, but they may inform the clinical management of those patients who have been di-

1 For example, so-called "dangerous" PD have received much attention in the UK due to a political and public awareness of their potential risk to others [59], whereas in Norway avoidant PD have been extensively described and investigated for years due to their perceived importance in this particular region $[60]$.

2 The present study only focused on the trait domain qualifiers. An optional borderline pattern qualifier was included in the ICD-11 to enhance clinical utility in terms of continuity with the well-established treatment guidelines for this disorder, and it may optionally be used after first having specified prominent trait qualifiers. agnosed with a PD or personality difficulty, including how to establish a therapeutic alliance and decide on the target of the intervention [8]. Both ICD-11 and DSM-5 AMPD describe trait domains of negative affectivity, detachment, antagonism/dissociality, and disinhibition. In addition, the DSM-5 AMPD also includes a separate domain of psychoticism, whereas the ICD-11 includes a separate domain of anankastia.

In the present paper, we perceive 3 potential shortcomings of the DSM-5 AMPD and ICD-11 trait models ${ }^{2}$, respectively. First, the ICD-11 PD classification remains consistent with the ICD-10 tradition where schizotypy is understood as a variant of schizophrenia rather than a PD. For that reason, a domain of psychoticism is not included in the ICD-11 model. Nevertheless, a growing body of research and clinical knowledge suggest that trait features of schizotypy and psychoticism (e.g., oddity, thought disorder, and schizophrenia proneness) should not be ignored $[9,10]$. Second, the ICD-11 trait domain of Anankastia corresponds to the compulsivity trait domain, which was originally proposed as a separate domain for the DSM-5 trait model [11]. Ultimately this domain was omitted in the DSM-5 AMPD in favor of parsimony [12]. The DSM-5 AMPD defines features of anankastia/compulsivity (e.g., rigid perfectionism) in terms of low disinhibition, which is somewhat supported by empirical evidence $[13,14]$. Third, another difference between the DSM-5 AMPD trait model and the ICD-11 trait model is that the latter does not include any specific facets within the broader domains (e.g., grandiosity, deceitfulness, and manipulativeness within the domain of antagonism). Taken together, we propose that the aforementioned 3 potential shortcomings might be addressed using a combined assessment framework that operationalizes all 6 domains (including separate domains of psychoticism and anankastia) along with 3 primary facet level features for each domain. It might be worthwhile to consider such a common 6-factor framework in the progress toward DSM-5.1.

\section{A Feasible Approach to Measuring ICD-11 and DSM-5 Trait Domains and Facets}

Initially, the 220-item Personality Inventory for DSM5 (PID-5) was constructed to operationalize the DSM-5 AMPD trait model [12]. So far, several forms and scales have been developed from this PID-5 item-pool, including abbreviated forms $[15,16]$ and an algorithm for capturing 5 ICD-11 trait domains $[17,18]$ with 16 DSM-5 trait facets. Most recently an algorithm was developed for assessment of the combined DSM-5 AMPD and ICD-11 
trait model by means of 6 distinct domains (i.e., negative affectivity, detachment, antagonism, disinhibition, anankastia, and psychoticism), including 17 lower-order facets with a total of 34 items. It is the Personality Inventory for DSM-5 - Brief Form Plus (PID5BF+) [19]. In the present study we developed and employed a modified 36-item version of the PID5BF+, which is further described in Materials and Methods.

\section{Goal of the Present Study}

The present study sought to investigate and replicate the proposed 6-factor model of the combined ICD-11 and DSM-5 trait domains using a modified version of the PID5BF+ algorithm on international PID-5 data. Additionally, we aimed to investigate the associations between the 6 trait domains and the 10 familiar DSM-5 PD in order to determine continuity between traditional PD types and the combined DSM-5/ICD-11 traits. We expected the pattern of associations to be consistent with previous research on these domains in relation to familiar PD types $[20,21]$.

\section{Materials and Methods}

\section{Instruments}

In the current study we employed a modified version of the PID5BF+ [19], which comprises 36 items that were used to measure 6 domains by means of 18 facets.

The original PID5BF+ is a 34-item self-report form developed from the original PID-5 item pool to delineate the combined DSM5 and ICD-11 trait features within 6 domains (i.e., negative affectivity, detachment, antagonism, disinhibition, anankastia, and psychoticism). The selection of the $34 \mathrm{PID} 5 \mathrm{BF}+$ items was done by Kerber et al. [19] using ant colony optimization algorithms, which is a computational method that has been proven to be very effective for item selection tasks. For further details about the construction of the PID5BF+ we refer to Kerber et al. [19]. This original PID5BF+ consists of 34 items which operationalize the 6 domains by means of 17 primary facets that are largely supported by metaanalytic findings in terms of high expected loadings and low unexpected loadings across the higher-order domains [13]. The PID$5 \mathrm{BF}+$ operationalizes the domain of anankastia as a separate domain by the facets of rigid perfectionism (i.e., low disinhibition) and perseveration (i.e., negative affectivity), which is based on an empirically derived cross-walk between DSM-5 AMPD and ICD11 trait domains $[21,22]$.

In order to further adapt the PID5BF+ to efficiently capture the primary facets represented in the ICD-11 domain of anankastia, we modified its operationalization by extracting subfacets of orderliness, rigidity, and perfectionism from the composite facet of rigid perfectionism. The extraction of these 3 anankastia facets is consistent with the initial 37-facet version of the DSM-5 trait model [12]. Accordingly, orderliness, rigidity, and perfectionism were initially distinct facets which were subsequently collapsed into 1 composite facet of rigid perfectionism due to considerable intercorrelations [12]. For the perfectionism facet, we used 2 PID-5 items that were already selected for the PID5BF+ operationalization of rigid perfectionism (item 123 and item 176). For the rigidity facet, we used the only 2 items from the PID- 5 that covered this feature (item 140 and item 220). For the orderliness facet, we included 2 out of 4 possible items from the PID-5 (item 34 and item 115), which were selected based on their empirical item characteristics (i.e., item-scale correlations and internal consistency). Moreover, in this modified version of PID5BF+ we omitted perseveration ( 2 items) as a primary feature of anankastia because this facet was originally intended to capture features of negative affectivity as reflected by its expected loadings on the negative affectivity domain [13]. The other 30 items from the original PID5BF+ representing the 5 DSM-5 trait domains remained unchanged. The modified PID5BF+ scoring key is included in online supplementary Appendix A.

The present study used a modified PID5BF+ to operationalize the DSM-5 and ICD-11 trait domains using 3 primary facets per domain (Table 2), so that all domains are represented by an equal (and comparable) number of trait indicators. The complete modified PID5BF+ comprises 36 items, which delineate 18 facets $(2$ items per facet). The 6 domain scores are estimated using average scores for each domain's 3 primary facets. All of the analyzed PID$5 \mathrm{BF}+$ data in the present study were derived from international samples, where the original 220-item PID-5 [12] had been administered.

We employed the Structured Clinical Interview for DSM-IV Axis II (SCID-II) [23] as a diagnostic interview for PD in a clinical subsample $(n=142)$, which was derived from the Danish patient sample [see details in 24].

\section{Samples and Procedures}

In the present international collaborative study we included a total of 16 samples from different countries, regions, and populations [17, 19, 25-37]. In order to ensure heterogeneity and evade range restriction, we deliberatively incorporated diverse samples including clinical, community, student, and mixed samples. Thus, all of the data have already been analyzed, described, and published elsewhere using complete 220-item PID-5 data (see references in Table 1).

To ensure valid data, we systematically employed the PID-5 Response Inconsistency Scale (PID-5-RIS) for all samples to detect and exclude cases with random responding. The PID-5-RIS was developed by Keeley et al. [38] and subsequently validated in different studies $[35,39,40]$. We consistently excluded cases with a PID-5-RIS score of 17 or above, which is supported by the aforementioned findings. As presented and characterized in Table 1, the present study included 3 derivation samples (online suppl. Appendices 1-3) followed by 13 replication samples (online suppl. Appendices 4-13). For detailed sample and scale characteristics as well as data collection procedures for each sample, please consult the respective reference and the online supplementary material.

\section{Statistical Approach}

To test whether we could identify and replicate an empirically sound 6-factor structure of the combined ICD-11 and DSM-5 primary trait facets, we subjected a polychoric correlation matrix of the 18 facet scores of the modified PID5BF+ to an exploratory structural equation modeling analysis in Mplus 7.3 with robust 
Table 1. Model fit indices for ESEM 6-factor structure across international samples

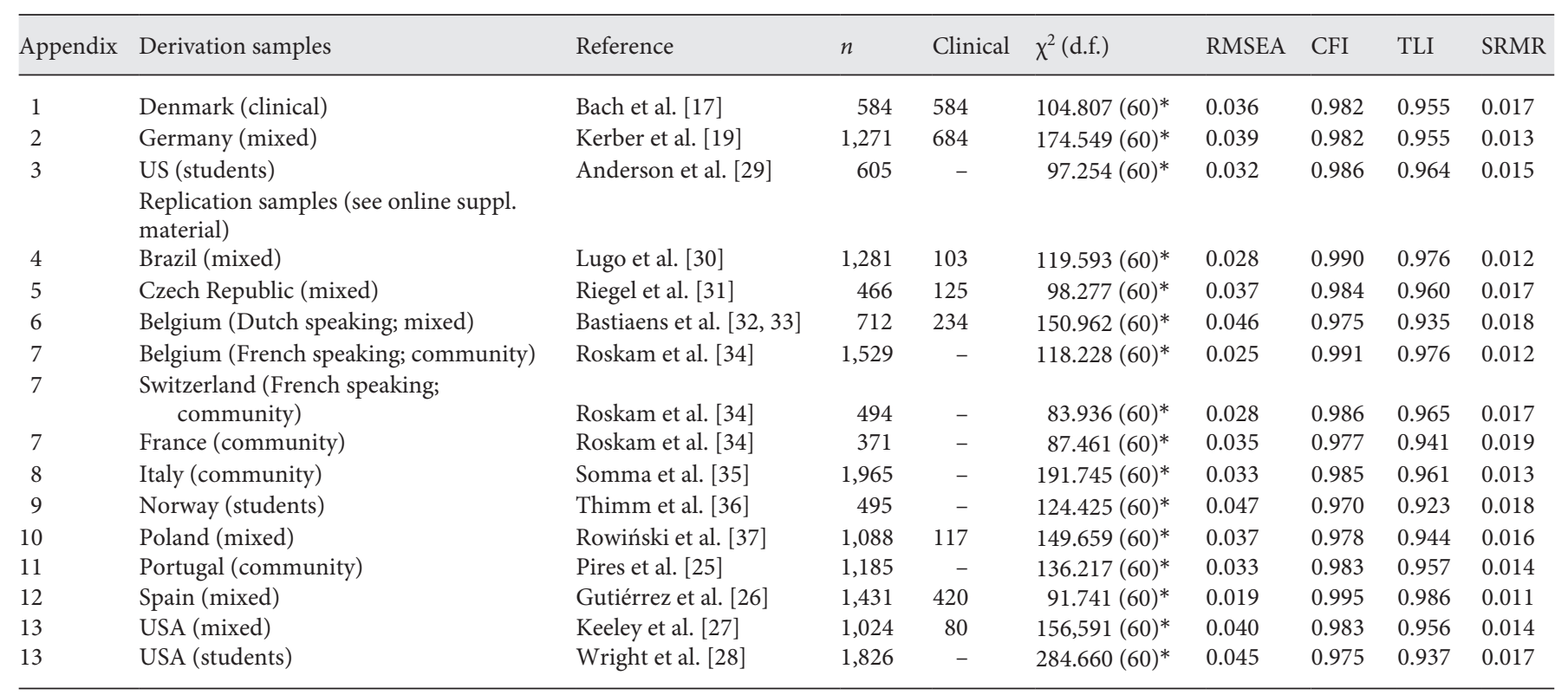

TLI, Tucker-Lewis index; SRMR, standardized root mean square residual; clinical, clinical participants; community, community-dwelling participants; mixed, both clinical and community; student, university or college students. * Significant at the 0.05 level.

maximum likelihood estimation and the default GEOMIN rotation [41]. Model fit was evaluated using the root mean square error of approximation (RMSEA), the comparative fit index (CFI), the Tucker-Lewis index, and the standardized root mean squared residual. We relied on the CFI $(>0.95)$ and the RMSEA $(<0.06)$ as indicators of adequate model fit [42].

\section{Results}

Derivation and Replication of the 6-Factor Structure

As presented in Table 1, model fit indices were good for the 6-factor structure across the 3 derivation samples (i.e., Denmark, Germany, and the USA) in terms of CFI above 0.95 and RMSEA below 0.06 . As presented in Table 2 , the 6 -factor model showed expected patterns for all 6 factors in terms of loadings above 0.40 . Only the facets of distractibility (Denmark) and perceptual dysregulation (USA) showed loadings slightly below 0.40 .

As shown in Table 1, the 13 international replication samples also showed good model fit indices in terms of CFI above 0.95 and RMSEA below 0.06 . As presented in online supplemental Appendices 4-13, each replication sample overall showed expected factorial patterns, with only few deviations that particularly applied to the facets of distractibility and irresponsibility. Accordingly, in both the Czech sample [31], the US mixed sample [27], and the US student sample [28], distractibility cross-loaded on negative affectivity and psychoticism. Likewise, in the French community sample [34], the Swiss community sample [34], the Portuguese community sample [25], and the Spanish mixed sample [26], irresponsibility primarily loaded negatively on anankastia rather than disinhibition. Moreover, in the Brazilian mixed sample [30] impulsivity cross-loaded on negative affectivity, whereas in the Swiss sample impulsivity cross-loaded on antagonism. Finally, in the Swiss sample grandiosity cross-loaded on negative affectivity.

As shown in Table 2 (and suppl. Appendices 4-13), the latent factor correlations generally indicated appropriate discriminant validity. Some differences did occur across samples in the strength and pattern of correlation coefficients among trait domains ${ }^{3}$.

\section{Association with Interview-Rated PD}

As shown in Table 3, the associations of interview-rated PD with DSM-5 and ICD-11 trait domains were overall consistent with meta-analytic findings on the DSM- 5 Sec-

\footnotetext{
3 Associations between disinhibition and negative affectivity differed between cultures, with Spain having the strongest (i.e., 0.41) and France having the lowest (i.e., 0.20) values. Additionally, associations of psychoticism with disinhibition and psychoticism with anankastia differed between samples.
} 


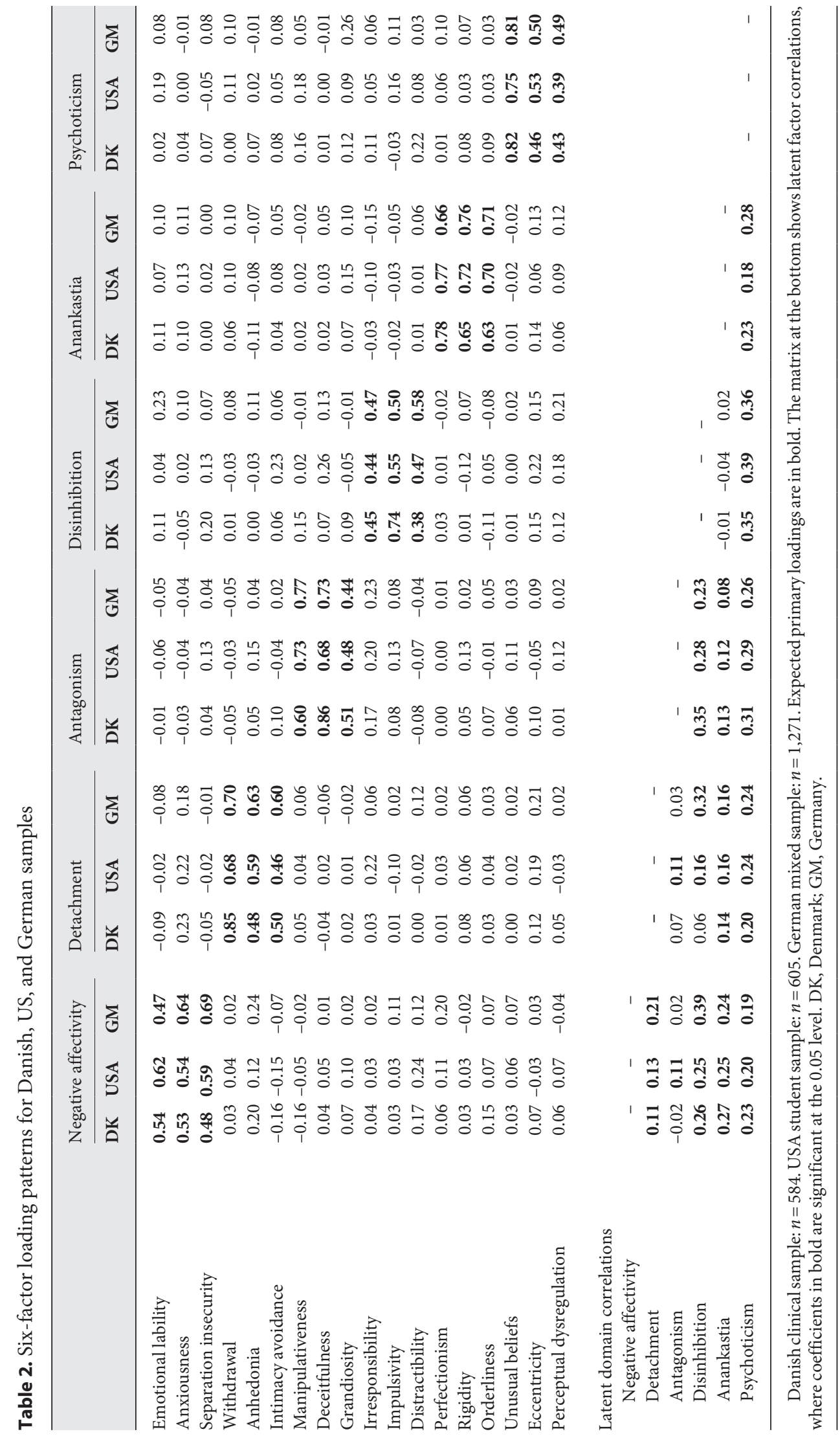


Table 3. Association with interview-rated DSM-5 PD criterion counts

\begin{tabular}{lcccccc}
\hline \multicolumn{7}{c}{} \\
\cline { 2 - 6 } & $\begin{array}{l}\text { Modified PID5BF+ ICD-11 and DSM-5 trait domains } \\
\text { negative } \\
\text { affectivity }\end{array}$ & detachment & antagonism & disinhibition & anankastia & psychoticism \\
\hline Paranoid & 0.37 & 0.29 & 0.33 & 0.23 & 0.21 & 0.36 \\
Schizoid & -0.18 & 0.28 & 0.22 & 0.06 & 0.05 & 0.14 \\
Schizotypal & 0.11 & 0.19 & 0.24 & 0.19 & 0.15 & 0.57 \\
Antisocial & -0.36 & 0.00 & 0.53 & 0.33 & 0.03 & 0.20 \\
Borderline & 0.45 & 0.25 & 0.25 & 0.44 & 0.25 & 0.35 \\
Histrionic & 0.26 & -0.04 & 0.36 & 0.36 & 0.22 & 0.21 \\
Narcissistic & -0.11 & -0.01 & 0.67 & 0.27 & 0.12 & 0.30 \\
Avoidant & 0.50 & 0.33 & -0.11 & 0.09 & 0.21 & 0.03 \\
Dependent & 0.47 & 0.16 & -0.01 & 0.30 & 0.05 & 0.22 \\
Obsessive-compulsive & 0.26 & 0.09 & 0.17 & 0.04 & 0.66 & 0.26 \\
\hline
\end{tabular}

$n=142$. All coefficients above 0.17 are significant at the 0.05 level, and coefficients above 0.21 are significant at the 0.001 level.

tion III [20] as well as research on the ICD-11 trait domains [21]. Paranoid PD was predominantly related to negative affectivity, psychoticism, antagonism, and detachment, in that order. Schizoid PD was related to Detachment and secondarily to antagonism and lack of negative affectivity. Schizotypal PD was related to psychoticism and secondarily to antagonism and detachment. Antisocial PD was related to antagonism, low negative affectivity, and disinhibition. Borderline PD was related to negative affectivity, disinhibition, and psychoticism. Histrionic $\mathrm{PD}$ was related to antagonism, disinhibition, and negative affectivity. Narcissistic PD was related to antagonism and secondarily to psychoticism and disinhibition. Avoidant PD was related to negative affectivity and detachment and secondarily to anankastia. Dependent PD was related to negative affectivity and disinhibition. Finally, obsessive-compulsive PD was related to anankastia and secondarily to negative affectivity and psychoticism.

In order to inspect the difference between the original $\mathrm{PID} 5 \mathrm{BF}+$ algorithm and the modified PID5BF+ algorithm, we compared their correlations with $\mathrm{PD}$ criterion counts. First, we found the modified PID5BF+ anankastia domain to be more strongly correlated with obsessivecompulsive PD $(r=0.66)$ relative to the original PID$5 \mathrm{BF}+$ anankastia domain $(r=0.48)$. Moreover, the original PID5BF+ anankastia domain showed a stronger mean correlation with other $\mathrm{PD}\left(r_{\mathrm{m}}=0.18\right)$ relative to the modified PID5BF+ anankastia domain $\left(r_{\mathrm{m}}=0.14\right)$. These patterns suggest that the modified PID5BF+ has better sensitivity and specificity for obsessive-compulsive PD relative to the original PID5BF+. However, both opera- tionalizations of anankastia seem useful for the purpose of capturing features of compulsivity. In any case, when correlating the original PID5BF+ anankastia score with the modified PID5BF+ anankastia score, using the mixed German sample, we found the 2 domain scores to be substantially overlapping $(r=0.80)$.

\section{Discussion}

In the present study we investigated and replicated a 6-factor model of the combined ICD-11 and DSM-5 trait domains (i.e., negative affectivity, detachment, antagonism, disinhibition, anankastia, and psychoticism) across international samples using a modified version of the PID5BF+ (36 items). We also found that the 6 modified $\mathrm{PID} 5 \mathrm{BF}+$ domains overall showed good discriminant validity and meaningful continuity with familiar interviewrated $\mathrm{PD}$, consistent with previous findings on the PID-5 $[20,21,24]$. Notably, this 6-domain structure of personality traits aligns with the 6-domain trait model originally proposed for DSM-5 [11]. In general, the 18 modified PID5BF+ facets showed expected loadings with good model fits across different countries and populations. The most evident deviating pattern applied to irresponsibility (negative cross-loading on anankastia) and distractibility (cross-loadings on negative affectivity and psychoticism), which is consistent with PID-5 research on ICD-11 traits [17] and DSM-5 traits [13], respectively. In the following sections, our findings will be further discussed in relation to the path going forward for ICD-11 and DSM-5.1. 


\section{A Feasible Facet-Level Portrait of ICD-11 Trait Qualifiers}

In contrast to the more parsimonious ICD-11 trait domain model, the DSM-5 AMPD trait system allows clinicians to specify 25 trait facets. According to the ICD-11 Working Group for the Revision of Personality Disorders, such facet level information was thought to add unnecessary complexity to the classification $[43,44]$. Nevertheless, reference to potential facet level features is included within the description of the five ICD-11 domains, but there is no coding for specific facets [7]. Even though ICD-11 trait qualifiers are only coded at the domain level, which seems most feasible for most WHO member countries, more specialized practitioners often desire a number of facet descriptors to guide their conceptualization and treatment planning [45]. The present study shows that primary features of each ICD-11 trait domain may be reliably and validly portrayed using specific DSM-5 trait facets, which also works across different countries and languages. In cases where practitioners or researchers would only want a profile of the 5 established ICD-11 trait domain qualifiers, the 6 items comprising the psychoticism domain may be omitted, which would yield a reduced 30-item version.

\section{Would DSM-5 Benefit from a Separate Domain of} Compulsivity/Anankastia?

The DSM-5 trait system describes features of anankastia/compulsivity in terms of a low score on disinhibition (i.e., rigid perfectionism). However, when looking at the latent factor correlations reported in Table 2 (and suppl. Appendices 4-13), there are no substantial negative correlations between disinhibition and anankastia, which somewhat speaks against using the low end of disinhibition as measure of anankastia as suggested in the DSM-5 proposal $[11,12]$. This is consistent with previous research supporting a distinct and psychometrically sound domain of anankastia $[17,46]$. Most importantly, it might not be straightforward or clinically meaningful for practitioners to specify a code for "low disinhibtion" or "lack of disinhibition" in order to highlight this trait feature, and lack of something does not necessarily mean presence of something else. In fact, it is not uncommon that a rather complex PD is characterized by both compulsivity and disinhibition [47], which therefore requires that these 2 features can be specified simultaneously using 2 separate codes. Also, when employed for research and screening purposes, it would not be possible to measure these 2 features at the same time if each were only represented by polar opposites within a single dimension (i.e.,

International Assessment of ICD-11 and DSM-5 Traits disinhibition vs. compulsivity dimension). Moreover, experts on compulsivity have called for a more multidimensional profile of anankastia in response to the current DSM-5 AMPD model in which compulsivity/anankastia is only represented by the facet of rigid perfectionism (low disinhibition) along with a secondary facet of perseveration (negative affectivity) $[48,49]$. Thus, we suggest that a future DSM-5.1 should include a separate domain of anankastia/compulsivity just as in the original PD proposal for DSM-5 [11]. We also endorse the inclusion of multiple facets of anankastia/compulsivity (e.g., perfectionism, orderliness, and rigidity), which can be represented by 2 items per facet as demonstrated in the present study.

\section{Issues Related to the Domain of Psychoticism and}

\section{Psychotic-Like Features}

In the initial DSM-5 proposal, the psychoticism domain was labelled "schizotypy" including facets of unusual perceptions, unusual beliefs, eccentricity, cognitive dysregulation, and dissociation proneness [11]. For empirical reasons, these facets were eventually collapsed into unusual beliefs and experiences, eccentricity, and cognitive and perceptual dysregulation within the higher-order domain of psychoticism [12], as operationalized in the present study. This maladaptive domain can be said to refer to a dimension ${ }^{4}$ ranging from normal dissociative, imaginative, and unconventional features to more extreme schizophrenia-like features (e.g." "Sometimes I can influence other people just by sending my thoughts to them."). On this continuum, the DSM-5 captures features of schizotypy that are closer to the "normal" end, characterized by eccentric appearance or some cognitive disorganization [50]. Thus, the DSM-5 definition of psychoticism can be said to refer to a normal variation of schizophrenia liability including features of dissociation proneness. Importantly, this schizotypal-oriented definition of psychoticism should not be equated with the broader concept of Eysenck [51] of psychoticism characterized by features such as aggressiveness, impulsivity, and creativity, which he believed were linked to vulnerability to psychosis. In other words, the concept of Eysenck [51] of psychoticism is more related to disinhibition and antagonism, whereas his trait of creativity may be somewhat related to psychoticism or schizotypy in terms of unconventionality [52]. Nevertheless, consistent with the

\footnotetext{
From the perspective of "polar opposites" the healthy end of this dimension may be conceptualized as "lucidity" [45].
} 
model of Eysenck [51], the majority of PID-5 research on psychoticism has shown substantial associations between psychoticism and disinhibition [13]. Likewise, the strongest interfactor correlations in the present study applied to these 2 domains (Table 2). Finally, the DSM-5 AMPD operationalization of psychoticism partially captures features of borderline PD in terms of cognitive and perceptual dysregulation, which includes features of dissociation proneness $[21,53,54]$.

In contrast to the DSM-5 approach (Sections II and III), the ICD-11 PD classification does not provide any code for schizotypy or psychoticism because such features are coded within schizophrenia and other primary psychotic disorders. However, many clinicians and researchers may stay loyal to the more familiar DSM-5 schizotypal personality features including the growing body of research, yet the ICD-11 classification of PD severity may rely on whether the patient experiences "dissociative states or psychotic-like beliefs or perceptions" and/or is "highly eccentric," which may resemble certain features of schizotypy or psychoticism. Accordingly, the ICD-11 approach is somewhat consistent with the traditional structural approach to classification of personality organization (e.g., neurotic, borderline, and psychotic levels), in which the lowest and most severe borderline levels may involve transient psychotic states [55]. In other words, the ICD-11 approach can be said to conceptualize and classify the capacity for reality testing (i.e., "accuracy of situational and interpersonal appraisals") according to level of PD severity, and not as a distinct trait domain [22].

Notably, the ICD-11 severity-related features of psychotic-like perceptions must be associated with situations of high affective arousal, which does not necessarily apply to the DSM-5 trait domain of psychoticism. For example, a person characterized by DSM-5 psychoticism may be able to live a satisfactory life with low distress despite eccentricity and somewhat odd beliefs. In contrast, a person characterized by ICD-11 severe PD with psychotic-like experiences in situations of high affective arousal may be viewed as having a highly vulnerable inner structure with strongly immature defense mechanisms when placed in unstructured situations or being under pressure [56]. Thus, the ICD-11 classification of PD severity according to "reality testing" may not simply be exchanged with the trait of psychoticism and vice versa.

We therefore propose that a future harmonization between ICD-11 and DSM-5.1 covers both the ICD-11 trait domains along with the current DSM-5 AMPD domain of psychoticism, which is consistent with the 6-domain model supported in the present study.
Towards a New PD Trait Model in DSM-5.1

It is important to underscore that the ICD-11 classification of PD is not just an "international" alternative to the American DSM-5 because, at the end of the day, the ICD-11 is the only authoritative nomenclature, even in countries such as the USA, Australia, and the UK. Thus, even the many practitioners who swear allegiance to the DSM-5 must eventually use the ICD-11 for coding purposes (e.g., national statistics, legal decisions, and health insurance). For this particular purpose, it seems reasonable that the DSM-5 framework aligns as much as possible with the ICD-11. Unless the American Psychiatric Association (APA) choses to forgo publishing another edition of the DSM and instead adopt the ICD-11 of the WHO (which could be an ideal solution), ${ }^{5}$ we believe that a future DSM-5.1 revision might be substantially improved by further alignment with the authoritative ICD11 in terms of including the same trait domain qualifiers, which is empirically supported in the present study across different countries and populations.

\section{Limitations and Future Directions}

The findings of the present study should be considered in the light of certain limitations and future directions. First, because the modified PID5BF+ data ( 36 items) used in the present study was extracted from complete 220item PID-5 data, we suggest that future research conduct independent evaluations of the 36-item modified PID$5 \mathrm{BF}+$ without using the algorithm for the complete 220item original PID-5. Second, the present study primarily included samples from Western, educated, industrialized, rich, and democratic (WEIRD) societies, and we therefore encourage future research to include samples from non-WEIRD countries in order to further generalize the global replicability [57]. Third, it was beyond the scope of the present study to employ more stringent tests of factor congruence and measurement invariance across countries, languages, gender, age groups, and clinical status, and we therefore encourage future research to pursue this aim. Fourth, future research should investigate convergence with another measure of ICD-11 traits such as the Personality Inventory for ICD-11 (PiCD) [58]. Finally, future research should aim to establish norm values from representative samples to guide interpretation of individual PID5BF+ test scores.

\footnotetext{
5 One official and freely accessible classification of mental disorders seems most appropriate and feasible for global mental health care, including WHO member countries that have local or independent classification systems (e.g., USA and Japan).
}

Bach et al. 


\section{Acknowledgement}

The present paper is dedicated to Erik Simonsen, MD, in celebration of his 70th birthday this year. Prof. Simonsen is a professor of Clinical Psychiatry at the Faculty of Health and Medical Sciences, University of Copenhagen, and founder and director of the Institute of Personality Theory and Psychopathology (IPTP) since 1989. As cofounder of the International Society for the Study of Personality Disorders (ISSPD), Prof. Simonsen spent much of his career paving the way for international dialogue within this field. More than 30 years ago, he invited prominent scholars and clinicians from around the world to the first ISSPD congress in Copenhagen, Denmark. Prof. Simonsen (in collaboration with Thomas A. Widiger) was later entrusted by the NIMH, the WHO, and the APA to take the lead in preparing the grounds for a reclassification of PD. He also founded the World Psychiatric Association (WPA) Section on Personality Disorders and chaired the WPA/ISSPD Educational Program on Personality Disorders. In the spirit of Prof. Simonsen's efforts for international dialogue and collaboration, the present work gathered contemporary PD researchers from around the world in order to establish the international validity of a feasible and empirically robust measure of PD traits that harmonizes and integrates the ICD-11 and the DSM-5 nosologies.

\section{Statement of Ethics}

This research was conducted ethically in accordance with the World Medical Association Declaration of Helsinki. Subjects have given their informed consent and ethical approval was not required due to the nature of this study.

\section{Disclosure Statement}

The authors have no conflict of interests to declare.

\section{Author Contributions}

B.B. drafted this paper and initiated data analyses in collaboration with J.Z., A.K., A.F., and A.S.; A.A., T.B., L.C., F.G., S.E.S.O., R.P., K.D.R., J.-P.R., I.R., M.S., A.S., L.S., W.S., J.C.T., J.W.K., and A.G.C.W. provided data and critically reviewed/revised this work.

\section{References}

1 Volkert J, Gablonski TC, Rabung S. Prevalence of personality disorders in the general adult population in Western countries: systematic review and meta-analysis. Br J Psychiatry. 2018 Dec;213(6):709-15.

2 Beckwith H, Moran PF, Reilly J. Personality disorder prevalence in psychiatric outpatients: a systematic literature review. Pers Ment Health. 2014 May;8(2):91-101.

3 Tyrer P, Reed GM, Crawford MJ. Classification, assessment, prevalence, and effect of personality disorder. Lancet. 2015 Feb; 385(9969):717-26.

4 Fossati A. European perspectives on personality disorders: knowing a complex history for a (hopefully) bright future. Pers Ment Health. 2011;5(2):132-43.

5 Keeley JW, Reed GM, Roberts MC, Evans SC, Medina-Mora ME, Robles R, et al. Developing a science of clinical utility in diagnostic classification systems field study strategies for ICD-11 mental and behavioral disorders. Am Psychol. 2016 Jan;71(1):3-16.

6 Zimmermann J, Kerber A, Rek K, Hopwood CJ, Krueger RF. A Brief but Comprehensive Review of Research on the Alternative DSM-5 Model for Personality Disorders. Curr Psychiatry Rep. 2019 Aug;21(9):92.

7 World Health Organization. ICD-11 clinical descriptions and diagnostic guidelines for mental and behavioural disorders. Geneva: WHO; 2019.

8 Bach B, Presnall-Shvorin J. Using DSM-5 and ICD-11 personality traits in clinical treatment. In: Gratz KL, Lejuez C, editors. Cambridge handbook of personality disorders. 1st ed. Cambridge: Cambridge University Press; 2020. p. 450-67.

9 Crego C, Widiger TA. The Conceptualization and Assessment of Schizotypal Traits: A Comparison of the FFSI and PID-5. J Pers Disord. 2017 Oct;31(5):606-23.

10 Lenzenweger MF. Schizotypy, schizotypic psychopathology and schizophrenia. World Psychiatry. 2018 Feb;17(1):25-6.

11 Skodol AE, Clark LA, Bender DS, Krueger RF, Morey LC, Verheul R, et al. Proposed changes in personality and personality disorder assessment and diagnosis for DSM-5 Part I: description and rationale. Pers Disord. 2011 Jan; 2(1):4-22.

12 Krueger RF, Derringer J, Markon KE, Watson D, Skodol AE. Initial construction of a maladaptive personality trait model and inventory for DSM-5. Psychol Med. 2012 Sep;42(9): 1879-90.

13 Watters CA, Bagby RM. A meta-analysis of the five-factor internal structure of the Personality Inventory for DSM-5. Psychol Assess. 2018 Sep;30(9):1255-60.

14 Bach B, El Abiddine FZ. Empirical structure of DSM-5 and ICD-11 personality disorder traits in Arab-speaking Algerian culture. Int J Ment Health. 2020;1-15.

15 Maples JL, Carter NT, Few LR, Crego C, Gore WL, Samuel DB, et al. Testing whether the DSM-5 personality disorder trait model can be measured with a reduced set of items: an item response theory investigation of the Personality Inventory for DSM-5. Psychol Assess. 2015 Dec;27(4): 1195-210.
16 Bach B, Maples-Keller JL, Bo S, Simonsen E. The alternative DSM-5 personality disorder traits criterion: A comparative examination of three self-report forms in a Danish population. Pers Disord. 2016 Apr;7(2):124-35.

17 Bach B, Sellbom M, Kongerslev M, Simonsen E, Krueger RF, Mulder R. Deriving ICD-11 personality disorder domains from dsm-5 traits: initial attempt to harmonize two diagnostic systems. Acta Psychiatr Scand. 2017 Jul;136(1):108-17.

18 Sellbom M, Solomon-Krakus S, Bach B, Bagby RM. Validation of Personality Inventory for DSM-5 (PID-5) algorithms to assess ICD11 personality trait domains in a psychiatric sample. Psychol Assess. 2020 Jan;32(1):40-9.

19 Kerber A, Schultze M, Müller S, Rühling RM, Wright AG, Spitzer C, Krueger RF, et al. Development of a short and ICD-11 compatible measure for DSM-5 maladaptive personality traits using ant colony optimization algorithms.. Available from: https://doi.org/ 10.31234/osf.io/rsw54.

20 Watters CA, Bagby RM, Sellbom M. Metaanalysis to derive an empirically based set of personality facet criteria for the alternative DSM-5 model for personality disorders. Personal Disord. 2019 Mar;10(2):97-104.

21 Bach B, Sellbom M, Skjernov M, Simonsen E. ICD-11 and DSM-5 personality trait domains capture categorical personality disorders: finding a common ground. Aust N Z J Psychiatry. 2018 May;52(5):425-34.

22 Bach B, First MB. Application of the ICD-11 classification of personality disorders. BMC Psychiatry. 2018 Oct;18(1):351. 
23 First MB, Gibbon M, Spitzer RL, Benjamin LS, Williams JB. User's guide for the structured clinical interview for DSM-IV axis II personality disorders: SCID-II. Washington: American Psychiatric Press; 1997.

24 Bach B, Anderson J, Simonsen E. Continuity between interview-rated personality disorders and self-reported DSM-5 traits in a Danish psychiatric sample. Pers Disord. 2017 Jul; 8(3):261-7.

25 Pires R, Sousa Ferreira A, Gonçalves B, Henriques-Calado J, Paulino M. The Portuguese version of the Personality Inventory for the DSM-5 in a community and a clinical sample. Pers Ment Health. 2019 Feb;13(1):40-52.

26 Gutiérrez F, Aluja A, Peri JM, Calvo N, Ferrer M, Baillés E, et al. Psychometric Properties of the Spanish PID-5 in a Clinical and a Community Sample. Assessment. 2017 Apr;24(3): 326-36.

27 Keeley JW, Flanagan EH, McCluskey DL. Functional impairment and the DSM-5 dimensional system for personality disorder. J Pers Disord. 2014 Oct;28(5):657-74.

28 Wright AG, Thomas KM, Hopwood CJ, Markon KE, Pincus AL, Krueger RF. The hierarchical structure of DSM-5 pathological personality traits. J Abnorm Psychol. 2012 Nov 121(4):951-7.

29 Anderson JL, Sellbom M, Bagby RM, Quilty LC, Veltri CO, Markon KE, et al. On the convergence between PSY-5 domains and PID-5 domains and facets: implications for assessment of DSM-5 personality traits. Assessment. 2013 Jun;20(3):286-94.

30 Lugo V, de Oliveira SE, Hessel CR, Monteiro RT, Pasche NL, Pavan G, et al. Evaluation of DSM-5 and ICD-11 personality traits using the Personality Inventory for DSM-5 (PID-5) in a Brazilian sample of psychiatric inpatients. Pers Ment Health. 2019 Feb;13(1):24-39.

31 Riegel KD, Ksinan AJ, Samankova D, Preiss M, Harsa P, Krueger RF. Unidimensionality of the personality inventory for DSM-5 facets: evidence from two Czech-speaking samples. Pers Ment Health. 2018 Nov;12(4):281-97.

32 Bastiaens T, Claes L, Smits D, De Clercq B, De Fruyt F, Rossi G, et al. The Construct Validity of the Dutch Personality Inventory for DSM5 Personality Disorders (PID-5) in a Clinical Sample. Assessment. 2016 Feb;23(1):42-51.

33 Bastiaens T, Smits D, De Hert M, Vanwalleghem D, Claes L. DSM-5 section III personality traits and section II personality disorders in a Flemish community sample. Psychiatry Res. 2016 Apr;238(2016):290-8.

34 Roskam I, Galdiolo S, Hansenne M, Massoudi $\mathrm{K}$, Rossier J, Gicquel L, et al. The Psychometric Properties of the French Version of the Personality Inventory for DSM-5. PLoS One. 2015 Jul;10(7):e0133413.
35 Somma A, Borroni S, Kelley SE, Edens JF, Fossati A. Further evidence for the validity of a response inconsistency scale for the Personality Inventory for DSM-5 in Italian community-dwelling adolescents, community-dwelling adults, and clinical adults. Psychol Assess. 2018 Jul;30(7):929-40.

36 Thimm JC, Jordan S, Bach B. Hierarchical Structure and Cross-Cultural Measurement Invariance of the Norwegian Version of the Personality Inventory for DSM-5. J Pers Assess. 2017 Mar-Apr;99(2):204-10.

37 Rowiński T, Kowalska-Dąbrowska M, Strus WS, Cieciuch J, Czuma I, Żechowski C, et al. Measurement of pathological personality traits according to Section III of the DSM-5: A Polish adaptation of PID-5. Part II - Empirical results. Psychiatr Pol. 2018 May; 2674(1):1-16

38 Keeley JW, Webb C, Peterson D, Roussin L, Flanagan EH. Development of a Response Inconsistency Scale for the Personality Inventory for DSM-5. J Pers Assess. 2016 Jul-Aug. 98(4):351-9.

39 Bagby RM, Sellbom M. The Validity and Clinical Utility of the Personality Inventory for DSM-5 Response Inconsistency Scale. J Pers Assess. 2018 Jul-Aug;100(4):398-405.

40 Lowmaster SE, Hartman MJ, Zimmermann J, Baldock ZC, Kurtz JE. Further validation of the Response Inconsistency Scale for the Personality Inventory for DSM-5. J Pers Assess. 2019 Oct; (Oct): 1-8.

41 Muthén LK, Muthén BO. Mplus user's guide. 6th ed. Los Angeles (CA): Muthén \& Muthén; 2012.

$42 \mathrm{Hu}$ LT, Bentler PM. Cutoff criteria for fit indexes in covariance structure analysis: conventional criteria versus new alternatives. Struct Equ Modeling. 1999;6(1):1-55.

43 Mulder RT, Newton-Howes G, Crawford MJ, Tyrer PJ. The central domains of personality pathology in psychiatric patients. J Pers Disord. 2011 Jun;25(3):364-77.

44 Tyrer P, Crawford M, Mulder RT, Blashfield R, Farnam A, Fossati A, et al. The rationale for the reclassification of personality disorder in the 11th revision of the International Classification of Diseases (ICD-11). Pers Ment Health. 2011 Nov;5(4):246-59.

45 Bach B, Markon K, Simonsen E, Krueger RF. Clinical utility of the DSM-5 alternative model of personality disorders: six cases from practice. J Psychiatr Pract. 2015 Jan;21(1):325.
46 Mulder RT, Horwood J, Tyrer P, Carter J, Joyce PR. Validating the proposed ICD-11 domains. Pers Ment Health. 2016 May;10(2): 84-95.

47 Chamberlain SR, Stochl J, Redden SA, Grant JE. Latent traits of impulsivity and compulsivity: toward dimensional psychiatry. Psychol Med. 2018 Apr;48(5):810-21.

48 Ayearst LE, Flett GL, Hewitt PL. Where is multidimensional perfectionism in DSM-5? A question posed to the DSM- 5 personality and personality disorders work group. Pers Disord. 2012 Oct;3(4):458-69.

49 Stoeber J. Multidimensional perfectionism and the DSM-5 personality traits. Pers Individ Dif. 2014 Jul;64:115-20.

50 Rawlings D, Williams B, Haslam N, Claridge G. Taxometric analysis supports a dimensional latent structure for schizotypy. Pers Individ Dif. 2008;44(8):1640-51.

51 Eysenck HJ. The definition and measurement of psychoticism. Pers Individ Dif. 1992;13(7): $757-85$.

52 Widiger TA, Simonsen E. Alternative dimensional models of personality disorder: finding a common ground. J Pers Disord. 2005 Apr; 19(2):110-30.

53 Sellbom M, Sansone RA, Songer DA, Anderson JL. Convergence between DSM-5 Section II and Section III diagnostic criteria for borderline personality disorder. Aust N Z J Psychiatry. 2014 Apr;48(4):325-32.

54 Bach B, Sellbom M. Continuity between DSM-5 Categorical Criteria and Traits Criteria for Borderline Personality Disorder. Can J Psychiatry. 2016 Aug;61(8):489-94.

55 Caligor E, Kernberg OF, Clarkin JF, Yeomans FE. Psychodynamic Therapy for Personality Pathology: Treating Self and Interpersonal Functioning. Arlington, VA, US: American Psychiatric Publishing; 2018.

56 Skodol AE, Gunderson JG, Pfohl B, Widiger TA, Livesley WJ, Siever LJ. The borderline diagnosis I: psychopathology, comorbidity, and personality structure. Biol Psychiatry. 2002 Jun;51(12):936-50.

57 Henrich J, Heine SJ, Norenzayan A. The weirdest people in the world? Behav Brain Sci. 2010 Jun;33(2-3):61-83.

58 Oltmanns JR, Widiger TA. A self-report measure for the ICD-11 dimensional trait model proposal: the personality inventory for ICD11. Psychol Assess. 2018 Feb;30(2):154-69.

59 Maden T, Tyrer P. Dangerous and severe personality disorders: a new personality concept from the United Kingdom. J Pers Disord. 2003 Dec;17(6):489-96.

60 Wilberg T, Karterud S, Pedersen G, Urnes $\varnothing$. The impact of avoidant personality disorder on psychosocial impairment is substantial. Nord J Psychiatry. 2009;63(5):390-6. 